\title{
Changes in Southern Hemisphere rainfall, circulation and weather systems
}

\author{
Frederiksen, J.S. ${ }^{1}$, C.S. Frederiksen ${ }^{2}$, S.L. Osbrough ${ }^{1}$ and J.M.Sisson $^{2}$ \\ ${ }^{I}$ Centre for Australian Weather and Climate Research, CSIRO Marine and Atmospheric Research, \\ Aspendale, Victoria, Australia \\ ${ }^{2}$ Centre for Australian Weather and Climate Research, Bureau of Meteorology, Docklands, Victoria, \\ Australia \\ Email:jorgen.frederiksen@,csiro.au
}

\begin{abstract}
During the last sixty years there have been large changes in the seasonal cycle of Southern Hemisphere circulation and reductions in rainfall particularly in the southern Australian region. Here we examine the corresponding changes in dynamical modes of variability during the annual cycle focusing on the mid-latitude storm track modes. We also discuss and analyze more briefly changes in other modes including onset of blocking modes and northwest cloud-band disturbances during southern winter. Our study builds on the work of Frederiksen and Frederiksen (2007) who examined the changes in southern hemisphere July storm tracks in twenty year periods before and after the mid-1970s. We employ a global two-level primitive equation instability-model and here we examine changes, during the periods 1949-1968, 1975-1994 and 1997-2006, in atmospheric modes of variability growing on reanalyzed observed three-dimensional basic states in the four seasons.
\end{abstract}

We relate the reduction in the rainfall in the southwest of Western Australia since the mid-1970s and in South-eastern Australia since the mid-1990s to changes in growth rate and structures of leading storm track and blocking modes. We find that cyclogenesis modes growing on the subtropical jet have significantly reduced growth rates in the latter periods. As well there is a reduction of the intensity of the subtropical storm track and increase in the polar storm track particularly in autumn and spring. On the other hand during winter there is a significant increase in the growth rate of northwest cloud-band modes and that cross Australia.

Southwest of Western Australia (SWWA) gets most of its rainfall in autumn and winter. We find that in winter there are considerable reductions in the growth rates (by around 30\%) of the leading storm track modes that cross southern Australia between the periods 1949-68 and 1975-94 (associated with the observed circa 20\% reduction in SWWA rainfall) and that these reductions continue into the period 1997-2007. In autumn growth rates of leading cyclogenesis modes with peak amplitudes across southern Australia decrease by between $10 \%$ and $20 \%$ between $1949-68$ and the latter periods. Importantly, during the more recent periods, storm activity increasingly moves from the latitudes of the subtropical jet to the latitudes of the polar jet. These changes in storm activity are consistent with and provide an explanation of the reduced rainfall over southwest of Western Australia since the mid 1970s.

In southeastern Australia the rainfall is spread more evenly throughout the year. We find that in spring there is only a very modest reduction (of around 5\%) in growth rates of the leading storm track modes that cross southern Australia between 1949-68 and 1975-94. However during the period 1997-2006 of drought the leading modes of storm activity tracked south of the Australian continent. Again, in summer there is a modest reduction (of around 10\%), between 1949-68 and 1975-94, in growth rates of the leading cyclogenesis modes that influence southeastern Australia. However, for the period 1997-2006 the storm activity largely misses southeastern Australia as the storm track has moved poleward. Again these changes in storm activity during 1997-2006 provide an explanation for the causes of the recent prolonged drought in southeastern Australia.

Keywords: Climate Modelling, Climate Change, Weather Systems, Southern Hemisphere Circulation 


\section{INTRODUCTION}

Major shifts in the structure of the large-scale circulation of the global atmosphere have occurred during the last sixty years or so (see Frederiksen and Frederiksen, 2007, for overview). During the second half of the $20^{\text {th }}$ century there have also been significant reductions in the rainfall across southern Australia and particularly across south west Western Australia (SWWA) (Smith 2004; Nicholls 2007; Bates et al. 2008; Frederiksen et al., 2010, 2011a, b; Risbey 2010). In this paper, the changes in Southern Hemisphere weather modes during the $20^{\text {th }}$ century are studied based on reanalyzed observations. We examine the decadal changes in leading dynamical modes of variability focusing on the behaviour of mid-latitude storms and how the changes vary with the seasonal cycle. We also discuss more briefly the roles of other weather systems such as blocking (Frederiksen and Frederiksen 1993b) and northwest cloud bands (Frederiksen and Frederiksen 1996). Frederiksen and Frederiksen (2007) showed that there had been a dramatic reduction in the growth rates of winter storm track modes crossing Australia in the 1975-1994 reanalyzes. Here, we examine the seasonal cycle of storm growth and the structures of the leading modes and how these properties have changed during the $20^{\text {th }}$ century including during the more recent period.

\section{PRIMITIVE EQUATION INSTABILITY MODEL}

The transient dynamical weather modes analyzed in this study have been obtained using the two-level linearized primitive equation model employed in a series of studies by Frederiksen and Frederiksen (1992, 1993a,b, 2007). The model includes a generalized Kuo-type heating parameterization that incorporates closures for both convection and evaporation-wind feedback. Each of the five perturbation fields and basic state fields, entering the linearized equations, is expanded in terms of spherical harmonics with the perturbations also having a time dependence $\exp (-i \omega t)$. Here $t$ is the time and $\omega=\omega_{r}+i \omega_{i}$ is the complex angular frequency with $\omega_{r}$ being the frequency, $T=2 \pi / \omega_{r}$ the period and $\omega_{i}$ the growth rate. This then results in a system of eigenvalue-eigenvector equations (Frederiksen and Frederiksen, 1992) for the streamfunction, potential temperature and velocity potential perturbation fields. A so-called rhomboidal 15 truncation is used for both the perturbation and basic state fields in which the zonal wave number $m=-15, \ldots, 0, \ldots, 15$ and the total wave number $n=|m|,|m|+1, \ldots,|m|+15$ in the spherical harmonic expansion. This corresponds to a resolution of $750 \mathrm{~km}$ by $500 \mathrm{~km}$ at $30^{\circ} \mathrm{S}$ in longitude by latitude. In this study we use the standard parameters for the strength of the convection, evaporation and dissipation, and pattern correlations $\mathrm{A}_{\mathrm{c}}$ between modes calculated over the five fields, as described in Frederiksen and Frederiksen (2007). The instability modes capture important properties of developing systems and their predictability (Frederiksen, 2000) while nonlinearity saturates the growth (Frederiksen, 1981).

The basic states employed in this study are the monthly averaged climate states for three time intervals 194968, 1975-94 and 1997-2006 obtained using the National centers for Environmental Prediction reanalyzes. We examine here the leading modes of variability for the middle months of each season, namely January, April, July and October.

\section{CHANGES IN THE SOUTHERN HEMISPHERE RAINFALL AND CIRCULATION}

Frederiksen and Frederiksen (2007) found that during the period 1975-1994 the peak strength of Southern Hemisphere (SH) July subtropical jet stream had reduced by 17\% compared with 1949-1968. This was accompanied by reductions in the instability of the SH atmosphere measured by the $300 \mathrm{hPa}$ minus $700 \mathrm{hPa}$ zonal wind shear. In the companion paper by Frederiksen et al. (2011c) we describe in detail how the trends in the baroclinic instability of the SH atmosphere over the period 1950-1999 vary with months during the annual cycle. As noted in that study, there are many similarities between the changes in baroclinic instability in July, described by Frederiksen and Frederiksen (2007), and the results found for other months, including a reduction over time, between latitudes $30^{\circ} \mathrm{S}$ and $40^{\circ} \mathrm{S}$, stretching across much of the Southern hemisphere.

Frederiksen and Frederiksen (2007) found that the changes in the July atmospheric circulation, particularly the baroclinicity, between the periods 1949-68 and 1975-94 also reflected in a significant reduction in the growth rate of leading storm track modes crossing Australia and with large amplitude over SWWA. They argued that a primary cause of the reduction of winter rainfall over SWWA in the period after 1975 is the reduction in the growth rate of mid-latitude storms and the southward deflection of some storms. The changes in Australian July rainfall between 1949-68 and 1975-94 was discussed in detail in the study of Frederiksen et al. (2011a) and is depicted in their Figure 1. The reduction in rainfall over SWWA has continued, and spread to the south east (Bates et al., 2008); southern Australia experienced drought during the final period 1997-2006 considered in this study. 


\section{SUMMER STORM TRACK MODES}

The leading Southern Hemisphere storm track, or cyclogenesis, modes for January in the three time intervals 1949-68, 1975-94 and 1997-2006 are in each case the fastest growing mode 1 for the respective intervals. Their periods and growth rates are respectively (2.0 days, 0.460 day $\left.^{-1}\right),\left(1.9\right.$ days, 0.417 day $\left.^{-1}\right)$ and (1.8 days, 0.440 day $^{-1}$ ). Thus there is a modest reduction of $9 \%$ in the growth rate in 1975-94 compared with the early time interval while for 1997-2006 this reduction is only 4\%. However, there are significant structural differences in the mode in the final time interval. The pattern correlation between mode 1 for 1949-68 and mode 1 for 1975-94 is $\mathrm{A}_{\mathrm{c}}=0.95$ while this drops to 0.65 for the correlation with mode 1 for 1997-2006. These differences are reflected in the structures of the modes, as shown in Figure 1 for the $700 \mathrm{hPa}$ streamfunctions for mode 1 for 1949-68 and mode 1 for 1997-2006. For the early period, mode 1 has largest amplitude at the longitudes of the Australia and New Zealand and significant amplitude across south-eastern Australia. In contrast, for the most recent period mode 1 misses Australia altogether and has largest amplitudes upstream and to the south of Australia. These differences in the modal properties between the early and more recent intervals are also reflected by the classes of the 10 leading storm track modes.
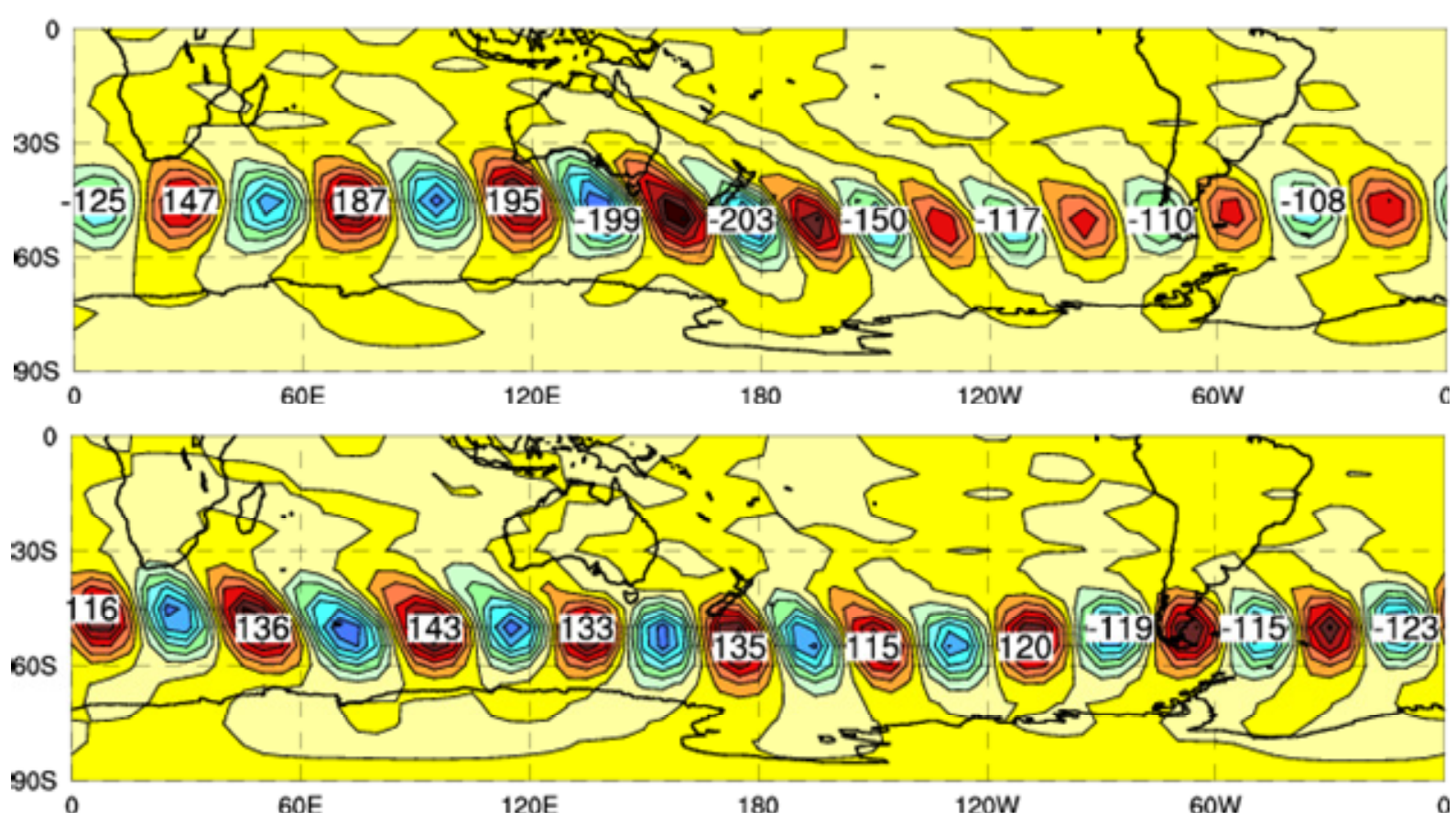

Figure 1. Disturbance streamfunction at $700 \mathrm{hPa}$ for January cyclogenesis mode 1 for $1949-68$ (top) and for mode 1 for 1997-2006 (bottom).

\section{AUTUMN STORM TRACK MODES}

For the time interval 1949-68, the leading SH April storm track mode are modes 8 and 9 with periods and growth rates of (2.6 days, 0.354 day $\left.^{-1}\right)$ and (4.0 days, 0.350 day $\left.^{-1}\right)$ respectively. For the time intervals $1975-$ 94 and 1997-2006 the leading SH storm track modes are modes 4 and 2 with periods and growth rates of (1.6 days, 0.394 day $\left.^{-1}\right)$ and (1.8 days, 0.395 day $\left.^{-1}\right)$ respectively. The $700 \mathrm{hPa}$ streamfunctions for modes 8 and 9 for 1949-68 and mode 2 for 1997-2006 are shown in Figure 2. We notice that mode 8 for 1949-68 and mode 2 for 1997-2006 both have largest amplitudes near $50^{\circ} \mathrm{S}$ at the longitudes of Australia and New Zealand. Mode 2 for 1997-2006 has essentially no impact on Australia while mode 8 for 1949-68 has some minor impact on Tasmania and south-eastern Australia. Mode 4 for 1975-94 (not shown) and mode 2 for 1997-2006 are quite similar with pattern correlations of $\mathrm{A}_{\mathrm{c}}=0.938$. Mode 8 for $1949-68$ is also similar to these modes but in fact has larger pattern correlations with mode 3 for 1997-2006 $\left(\mathrm{A}_{\mathrm{c}}=0.737\right)$ and mode 19 for 1975-94 $\left(\mathrm{A}_{\mathrm{c}}=0.750\right)$.

In contrast to these leading modes, mode 9 for 1949-68 has a wavetrain crossing southern Australia as well as a wavetrain further south near $60^{\circ} \mathrm{S}$. So although mode 9 is very slightly slower growing than mode 8 for 1949-68 it has a much larger impact on the circulation and rainfall over southern Australia. For the later 
periods there are also modes like mode 9 but they are much slower growing. Mode 9 for 1949-68 has largest pattern correlation of 0.549 with mode 15 for $1975-94$ (with period $=1.5$ days and growth rate $=0.275$ day $^{-1}$ ) and of 0.592 with mode 20 for 1997-2006 (with period $=3.3$ days and growth rate $=0.300$ day $^{-1}$ ). Thus while
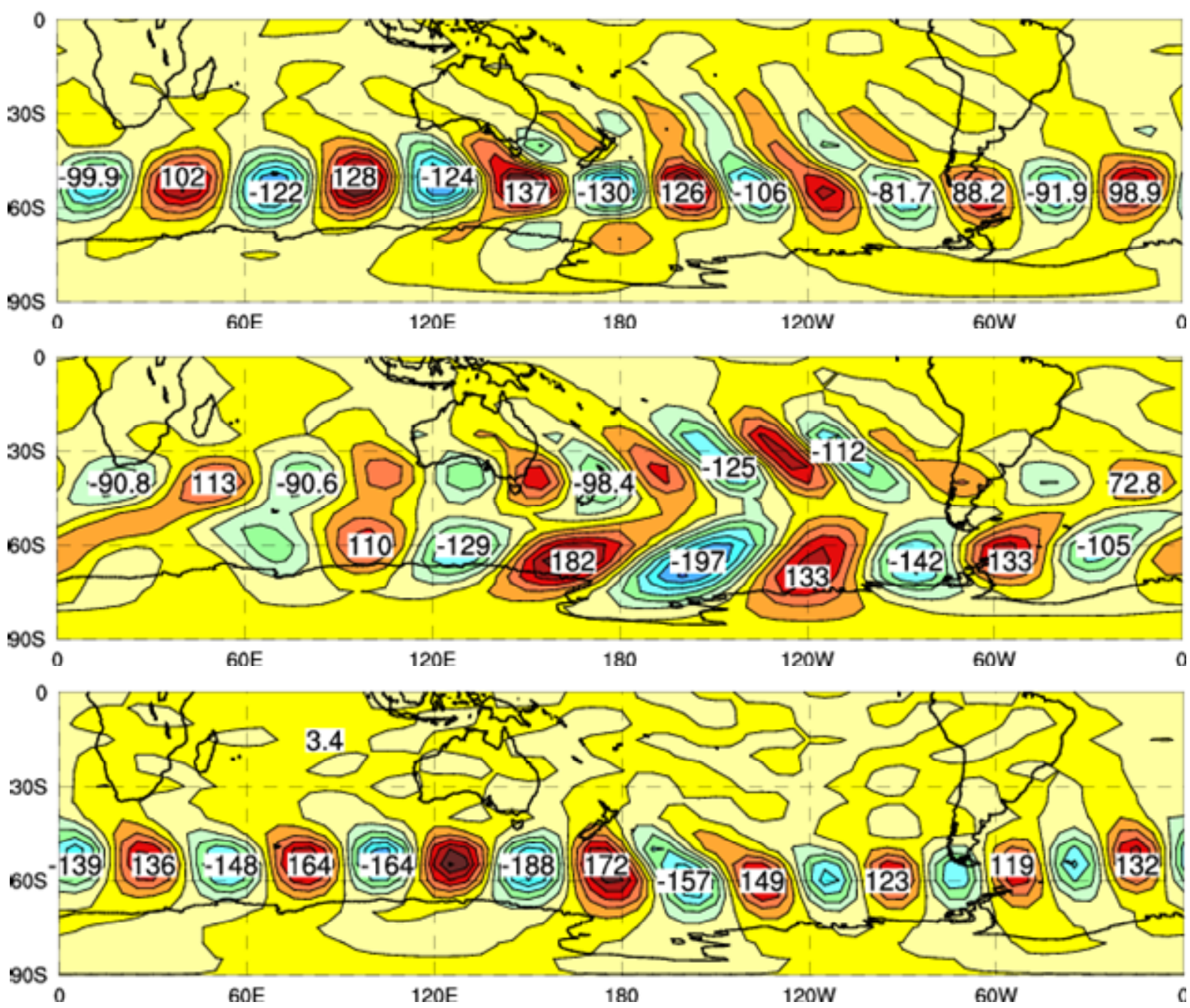

Figure 2. As in Figure 1 for leading April cyclogenesis mode (mode 8) (top) and dipole mode (mode 9) (middle) for 1949-68 and leading cyclogenesis mode (mode 2) for 1997-2006 (bottom).

the leading SH storm track modes for the later periods grow slightly faster than for the early period, for the storm track modes crossing southern Australia there are reductions in growth rates of $21 \%$ and $14 \%$ for 1975 94 and 1997-2006.

As discussed by Frederiksen et al. (2010), later in autumn the May reduction in the average growth rate of the 20 fastest growing storm track modes is around $10 \%$ in the more recent time intervals compared with 194968. There are also significant changes in the structures of the storm tracks with a movement of storm activity from the latitudes of the subtropical jet increasingly onto the latitudes of the polar jet.

\section{SPRING STORM TRACK MODES}

For October the leading storm track modes crossing Australia are mode 9 (with period $=2.6$ days and growth rate $\left.=0.291 \mathrm{day}^{-1}\right)$ for $1949-68$ and mode $6\left(\right.$ with period $=4.6$ days and growth rate $=0.276$ day $\left.^{-1}\right)$ for 1975 94 while for 1997-2006 the leading cyclogenesis mode is mode 7 (with period $=2.2$ days and growth rate $=$ 0.270 day $^{-1}$ ) which tracks to the south of Australia. Figure 3 shows the $700 \mathrm{hPa}$ streamfunctions for these modes. Mode 9 for 1949-68 is not closely related to any of the faster growing modes for 1975-94 or 19972006 in terms of scale and structure although it does track across Australia like the larger scale mode 6 for 1975-94. Mode 7 for 1997-2006 is most closely related to mode 16 for 1975-94 $\left(\mathrm{A}_{\mathrm{c}}=0.715\right)$ and mode 29 for 1949-68 $\left(\mathrm{A}_{\mathrm{c}}=0.629\right)$. As for autumn, in spring leading storm track modes that cross Australia have reduced 
growth rates in 1975-1994 compared with 1949-68 (by a modest 5\%) while during 1997-2006 the leading cyclogenesis mode tracks to the south of Australia.
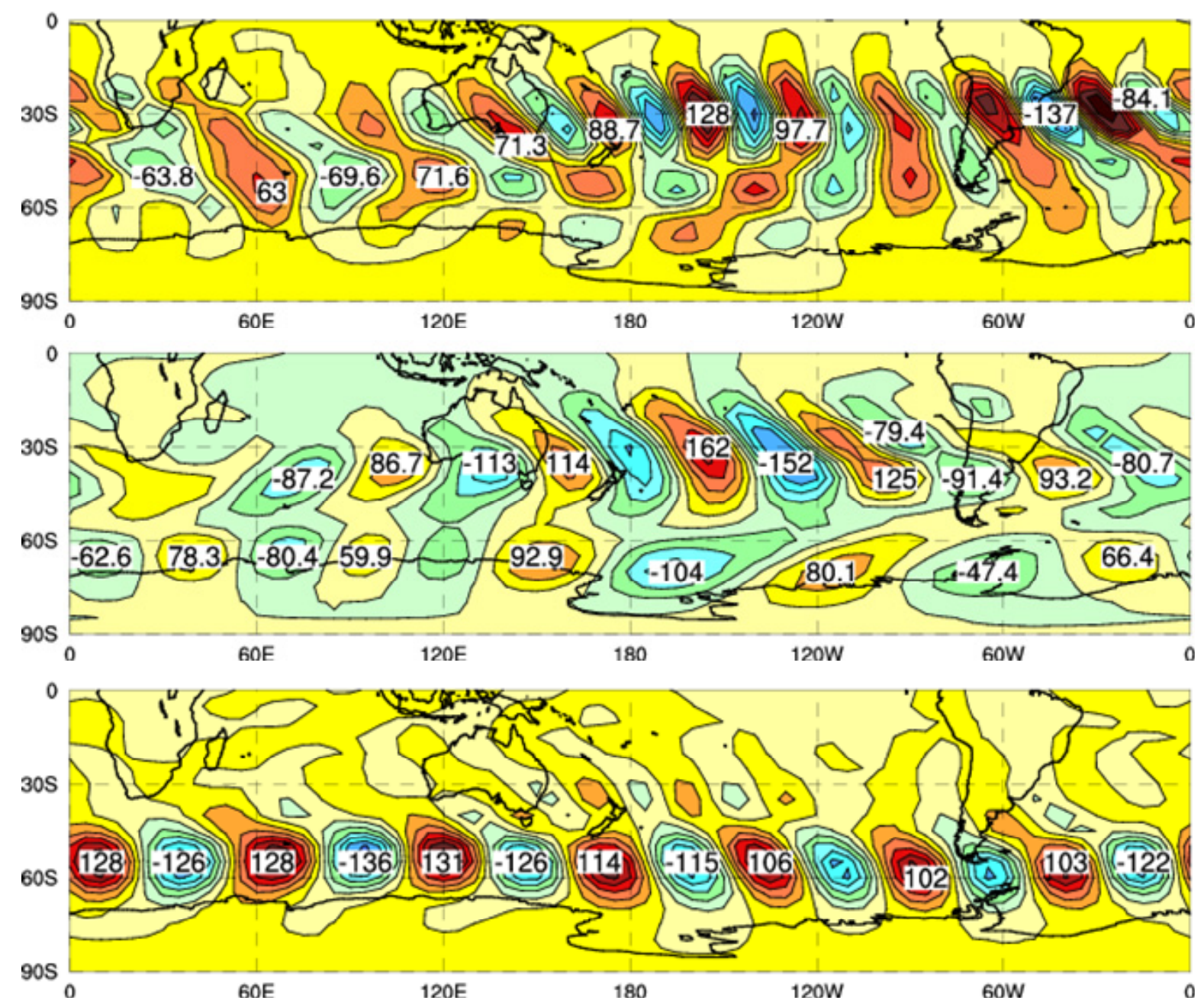

Figure 3. As in Figure 1 for leading October storm track mode crossing Australia (mode 9) for 1949-68 (top), leading storm track mode (mode 6) for 1975-94 (middle) and leading storm track mode (mode 7) for 19972006 (bottom).

\section{WINTER WEATHER MODES}

Next we examine classes of southern hemisphere July modes that have significant changes in properties during the three periods 1949-68, 1975-94 and 1997-2006.

The leading southern hemisphere storm track modes for the time intervals (1949-68, 1975-94, 1997-2006) are modes $(1,9,12)$. They all have periods of 1.3 days but growth rates of $\left(0.423\right.$ day $^{-1}, 0.282$ day $^{-1}, 0.266$ day $\left.^{-1}\right)$ and pattern correlations with mode 1 for $1949-68$ of $(1.0,0.915,0.896)$ respectively. This corresponds to reductions in growth rates of 33.5 per cent and 37.1 per cent during 1975-94 and 1997-2006 respectively. Figure 4 (upper panel) shows the $300 \mathrm{hPa}$ streamfunction for mode 12 for the 1997-2006 basic state. It is very similar to mode 1 for 1949-68 and mode 9 for 1975-94, as expected from their high pattern correlations. The disturbance has a wavenumber of around 12 in the regions of large amplitude over southern Australia and consists of a series of eastward propagating troughs and ridges. As the lows and highs move eastward they amplify to reach a maximum in preferred regions of large amplitude. The mode has largest amplitude focused over south-western Australia and secondary maxima over the central Southern Pacific Ocean; the divergence field has a very similar structure. We note that precipitation in our model is proportional to the magnitude of the upper level divergence, for which the maximum is focused over southern Australia. Thus the significant reduction in growth rates of storm track modes in the two latter time intervals is consistent with the reduction in rainfall over southern Australia and southwest Western Australia in particular, since the 1970s. Mode 12, 
shown in Figure 4 (upper panel) is the fastest growing of a class of cyclogenesis modes with zonal wavenumbers between 6 and 12 and large amplitudes in the Australian region.

For the time intervals (1949-68, 1975-94, 1997-2006), the leading southern hemisphere mid-latitude onset-
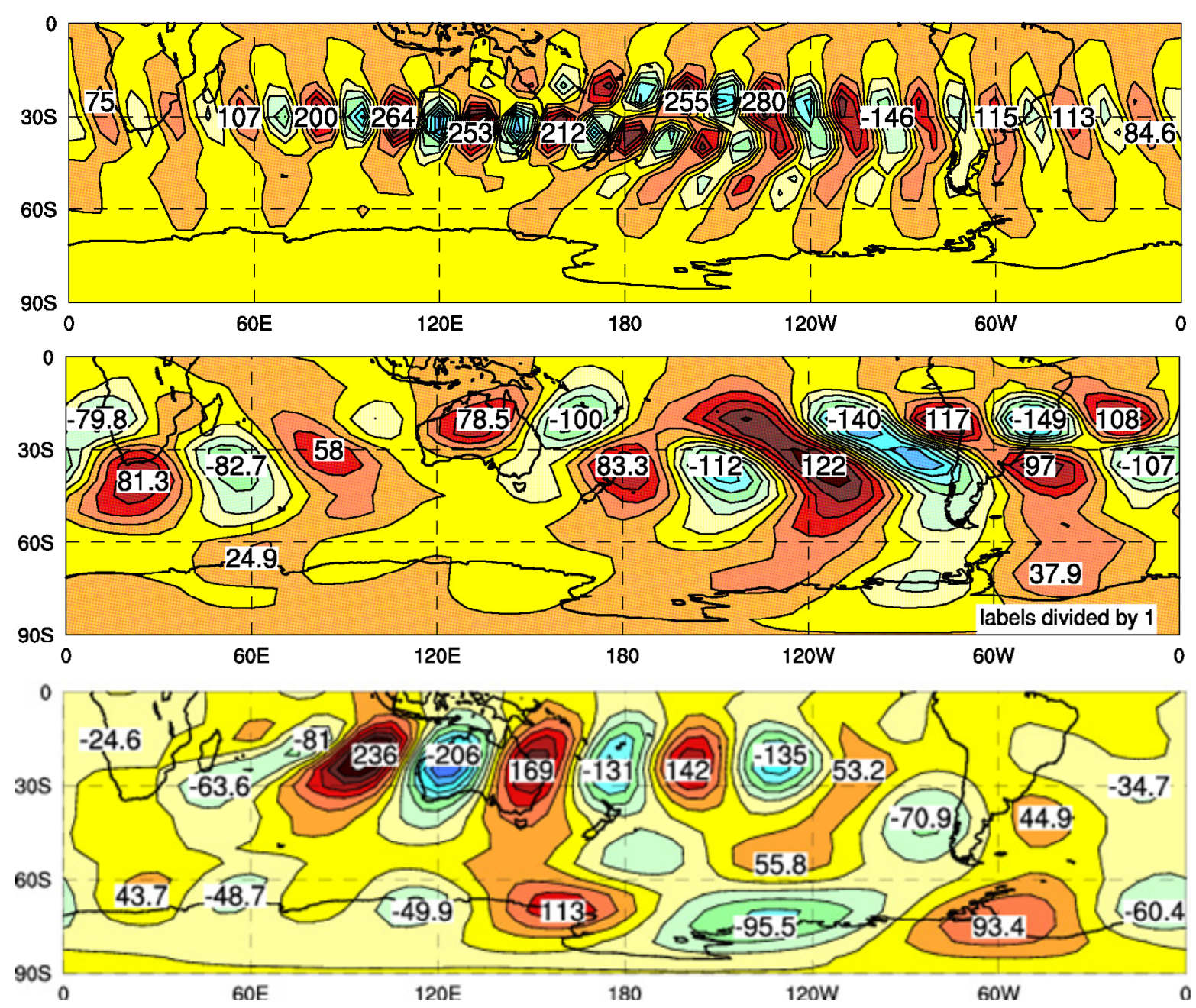

Figure 4. Disturbance streamfunction at $300 \mathrm{hPa}$ for July leading storm track mode (mode 12) (top), leading blocking mode (mode 26) (middle) and leading northwest cloud band mode (mode 7) (bottom) for 1997-2006.

of-blocking modes (Frederiksen and Frederiksen, 1993b) are modes (30, 21, 26), and all have periods of 6 days but growth rates of $\left(0.257\right.$ day $^{-1}, 0.228$ day $^{-1}, 0.207$ day $\left.^{-1}\right)$ and pattern correlations with mode 30 for $1949-68$ of $(1.0,0.460,0.640)$ respectively. Thus there are reductions in growth rates of 11.2 per cent and 19.2 per cent in 1975-94 and 1997-2006 compared with 1949-68. Mid-latitude, dipole, onset-of-blocking modes are eastward propagating, have longer periods than cyclogenesis modes (6 days compared with 1.3 days), and are of somewhat larger scale. They have dipole structures in the latitudinal direction in the major regions of observed southern hemisphere blocking Frederiksen and Frederiksen (1993b). Figure 4 (middle panel) shows an example of a mid-latitude onset-of-blocking mode (mode 26) for the 1997-2006 basic state; the $300 \mathrm{hPa}$ streamfunction has dipole structures between Australia and New Zealand, extending downstream over the central Pacific Ocean and as well there are dipole structures over the southern Atlantic Ocean. As noted above, for the time intervals 1949-68 and 1975-94, there are also onset-of-blocking modes with dipole wave-trains downstream of Australia, as in Figure 4. We expect that the growth rate reductions in 1975-94 and 1997-2006 compared with 1949-68 reflect the reductions in baroclinicity of the subtropical jet (that cause even greater reductions in the growth rate of storm track modes). The blocking highs in the region of New Zealand are also frequently associated with rain-bearing east-coast lows on the east coast of Australia.

The leading northwest cloud band (NWCB) modes for the time intervals (1949-68, 1975-94, 1997-2006) are modes $(43,12,7)$ and all have periods of 8 days but growth rates of $\left(0.210\right.$ day $^{-1}, 0.262$ day $^{-1}, 0.305$ day $\left.^{-1}\right)$ 
and pattern correlations with mode 43 for $1949-68$ of $(1.0,0.840,0.637)$ respectively. This corresponds to increases in growth rates of 24.9 per cent and 45.4 per cent during 1975-94 and 1997-2006 respectively. The NWCB modes are south-eastward propagating with periods of 8 days, although we also find slower growing NWCB modes with longer periods. Mode 7 for the 1997-2006 basic state is a NWCB mode that emanates from the region of the Indian Ocean, crosses Australia and then propagates into the central Pacific and south across South America. Figure 4 (bottom panel) shows the wavetrain of its $300 \mathrm{hPa}$ disturbance streamfunction. It differs significantly from the storm track and onset-of-blocking modes in that the NWCB growth rate for the time interval 1997-2006 is 45 per cent greater, and for 1975-94 is 25 per cent greater, than for the leading NWCB for the 1949-68 basic state. Again, the increased growth rates of the NWCB modes, in the later periods, are consistent with the rainfall trends (Frederiksen et al., 2011a).

\section{DISCUSSION AND CONCLUSIONS}

We have examined the changes in dynamical modes of variability during the annual cycle focusing on the mid-latitude storm track modes but also considering onset of blocking modes and northwest cloud-band disturbances during southern winter. We find that cyclogenesis modes crossing Australia have significantly reduced growth rates during 1975-94 and 1997-2006 compared with 1949-68. As well there is a reduction of the intensity of the subtropical storm track and increase in the polar storm track particularly in autumn and spring. In winter there is also a significant increase in the growth rate of northwest cloud-band modes cross Australia. Our results are consistent with the observed changes in Australian rainfall during the $20^{\text {th }}$ century.

\section{ACKNOWLEDGMENTS}

This research is supported by the Australian Government Department of Climate Change Science and Energy Efficiency, the Indian Ocean Climate Initiative of the West Australian Department of Environment, Water and Catchment Protection, and contributes to the research effort of the CSIRO Climate Adaptation Flagship.

\section{REFERENCES}

Bates, B.C., Hope, P., Ryan, B. et al., (2008), Key findings from the Indian Ocean Climate Initiative and their impact on policy development in Australia. Clim. Dyn., 89, 339-354.

Frederiksen, C.S. and Frederiksen, J.S. (1992), Northern hemisphere storm tracks and teleconnection patterns in primitive equation and quasigeostrophic models. J. Atmos. Sci., 49, 1443-1458.

Frederiksen, C.S. and Frederiksen, J.S. (1996), A theoretical model of Australian Northwest cloud band disturbances and Southern Hemisphere storm tracks: The role of SSTs. J. Atmos. Sci., 49, 1410-1432.

Frederiksen, C.S., Frederiksen, J.S., Sisson, J.M. and Osbrough, S.L., (2011a), Changes and projections in Australian winter rainfall: Anthropogenic forcing and internal variability, Int. J. Climate Change: Impacts and Responses, 2, 143-162.

Frederiksen, C.S., Frederiksen, J.S., Sisson, J.M. and Osbrough, S.L. (2011b), Australian winter circulation and rainfall changes and projections, Int. J. Climate Change Strategies and Management, 3, 170-188.

Frederiksen, C.S., Frederiksen, J.S., Sisson, J.M. and Osbrough, S.L., (2011c), Observed and projected changes in the annual cycle of Southern Hemisphere storm formation. Modsim11, submitted.

Frederiksen, J.S., (1981), Growth and vacillation cycles of disturbances in Southern Hemisphere flows. $J$. Atmos. Sci., 38, 1360-1375.

Frederiksen, J.S., (2000), Singular vectors, finite-time normal modes and error growth during blocking. $J$. Atmos. Sci., 57, 312-333.

Frederiksen, J.S. and Frederiksen, C.S., (1993a), Monsoon disturbances, intraseasonal oscillations, teleconnection patterns, blocking and storm tracks of the global atmosphere during January 1979: Linear theory. J. Atmos. Sci., 50, 1349-1372.

Frederiksen, J.S. and Frederiksen, C.S., (1993b), Southern Hemisphere storm tracks, blocking and low frequency anomalies in a primitive equation model. J. Atmos. Sci., 50, 3148-3168.

Frederiksen, J.S. and Frederiksen, C.S. (2007), Inter-decadal changes in Southern Hemisphere winter storm track modes. Tellus, 59 A, 559-617.

Frederiksen, J.S., C.S. Frederiksen, S.L. Osbrough and J.M. Sisson (2010), Causes of changing Southern Hemispheric weather systems, Managing Climate Change, CSIRO publishing, pp 85-98.

Nicholls, N. (2007), Detecting, Understanding and Attributing Climate Change. Australian Greenhouse Office Publication, 26pp.

Risbey, J.S. (2010), Dangerous climate change and water resources in Australia. Reg. Environ. Change, 11, S197-S203.

Smith, I. (2004), An assessment of recent trends in Australian rainfall. Aust. Met. Mag., 53, 163-173. 